\title{
One-Day-Shock, Two-Days-Shock and Three-Days-Shocks foF2 Diurnal Variation with Solar Cycle Phases at Ouagadougou Station from 1966 to 1998. Comparison with IRI 2012 Predictions
}

\author{
SEGDA Abdoul-kader ${ }^{1}$, GNABAHOU Doua Allain ${ }^{1} \&$ OUATTARA Frédéric ${ }^{1}$ \\ ${ }^{1}$ Laboratoire de Recherche en Energétique et Météorologie de l'Espace (LAREME), UFR - ST, Université \\ Norbert ZONGO, Koudougou, Burkina Faso \\ Correspondence: Frédéric OUATTARA, Laboratoire de Recherche en Energétique et Météorologie de l'Espace \\ (LAREME), UFR - ST, Université Norbert ZONGO, BP 376 Koudougou, Burkina Faso. E-mail: fojals@yahoo.fr
}

Received: October 6, 2019

doi:10.5539/apr.v12n1p38
Accepted: November 27, $2019 \quad$ Online Published: December 6, 2019

URL: http://dx.doi.org/10.5539/apr.v12n1p38

\begin{abstract}
The present work concerns foF 2 time variation at Ouagadougou station for three solar cycles (from cycle 20 to cycle 22). We not only investigate solar cycle phase dependence under shock activity that is divided into one-shock-activity, two-shock-activity and three-shock-activity but also compare the IRI 2012 model values with the data carried out at Ouagadougou station. This study reveals that there is no one-day-shock during solar minimum phase. For the other solar cycle phases IRI 2012 reproduces the ionosphere electrodynamics at daytime except during the increasing phase. During night time the model is not suitable. The best subroutine under one-day-shock activity is URSI for increasing and decreasing phases. During the maximum phase it is CCIR. For two-days-shock activity IRI 2012 reproduces the ionosphere electrodynamics during the minimum and the increasing phases. The best subroutine is CCIR during the minimum phase and URSI for the other solar cycle phases. For three-days-shock activity IRI 2012 is not suitable. The best model is URSI for all solar cycle phases.
\end{abstract}

Keywords: Shock Activity, One-Day-Shock, Two-Days-Shock, Three-Days-Shock, IRI, F2 Layer Critical Frequency

\section{Introduction}

By taking into account that ionospheric storms are closely associated with the geomagnetic storms (Sahai et al., 2001; Matsushita, 1959), we investigate the geomagnetic storm effect on the ionosphere F2 region. Here are concerned the storms due to coronal mass ejections (CMEs). This type of storm provokes the shock activity (Legrand \& Simon, 1989a, b; Richardson et al., 2000; Richardson \& Cane, 2002).

To exhibit the all geomagnetic activities and particularly that of shock, the pixel diagram (see Figure 1: for more details about the description and the used of this diagram see (Ouattara \& Amory Mazaudier, 2009) and the references therein) is a good tool.

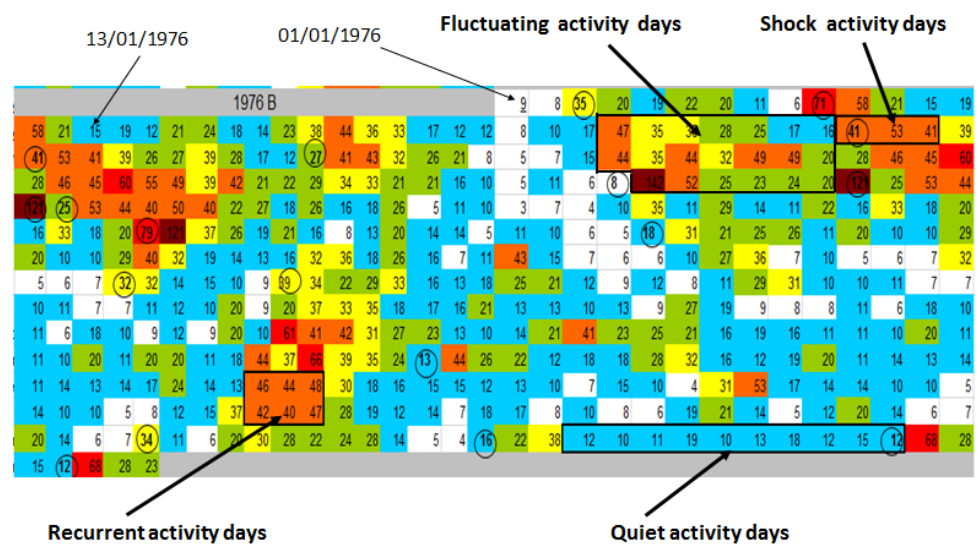

Figure 1. Year 1976 pixel diagram 
The used of the pixel diagrams allows (Gyébré et al., 2018) to classify each shock activity into three types (1) one-day-shock [its action time duration on the ionosphere does not exceed one day], (2) two-days-shock [its action time duration on the ionosphere is more than one day and does not exceed two days] and three-days-shock [its action time duration on the ionosphere is more than two days and does not exceed three days] (see figure 2 below). The investigation of shock activity impact on the ionosphere at Ouagadougou ionosonde station (Lat: $12.4^{\circ} \mathrm{N}$; Long: $358.5^{\circ} \mathrm{E}$; dip: $1.43^{\circ}$ ) F2 layer critical frequency (foF2) will be made by addressing the three types of shock previously identifying by (Gyébré et al., 2018). After the work of (Gyébré et al., 2018) which contribute to the challenge of identifying /understanding the nonlinear interaction among the thermosphere, ionosphere and magnetosphere during geomagnetic storms (Mendillo, 2006), in the present study, we evaluate, analyze and compare the predictions of IRI 2012 with foF 2 values carried out at Ouagadougou station with respect to each type of shock. This constitutes the novelty of our paper because according to (Gyébré et al., 2018) instead of treating a particularly shock event (short time variation, effect of storm time different phases with respect to Dst [disturbance storm time] time variation) or address statistical ionosphere F2 layer parameters variability under individual storm activity (e.g. Prölss, 1995; Fuller-Rowell et al., 1997; Lu et al., 1998; Buonsonto, 1999; Pi, 2000; Sastri, 2002; Goncharenko et al., 2005; Yizengaw et al., 2005). In the present paper, by testing IRI model, we expect to contribute to improve its predictability in this sector of latitude. Are involved during the period of 1966 to 1998,323 shock days with 168 days of the one-day-shock, 105 days of the two-days-shock and 50 days of the three-days-shock.

The second section devoted to materials and methods is followed by the third section that concerns the results and discussions. The conclusion section ends the present paper.

\section{Materials and Methods}

The data used here concern two solar cycles (cycles 21 and 22) F2 layer critical frequency (foF2) carried out at Ouagadougou station (Lat: $12.4^{\circ} \mathrm{N}$; Long: $358.5^{\circ} \mathrm{E}$; dip: $1.43^{\circ}$ ). For this study we focus our attention on the impact of the geomagnetic shock activity on foF2 time variation. According to (Gyébré et al., 2018) this class of activity can be divided into three types of shock: one-day-shock, two-days-shock and three-days-shock. These types (see Figure 2) are characterized by their time duration since the day of the occurrence of the Sudden Storm Commencement (SSC) [shown by encircled data] and zero (one-day-shock), one (two-days-shock) or two days (three-days-shock) after that day (see Figure 2).

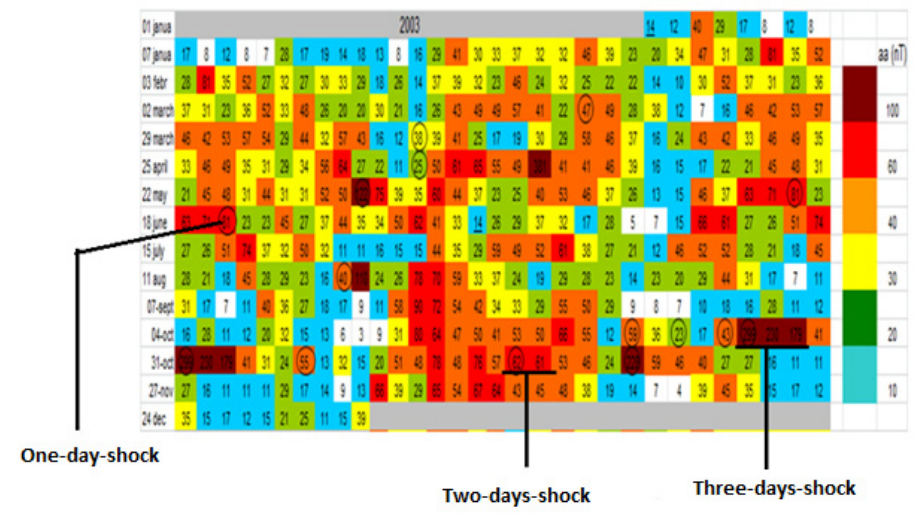

Figure 2. Different types of shock activity in the pixel diagram of the year 2003 (after Ouattara et al., 2015)

This paper analyses foF2 time variation during the three types of shock activity under the four solar cycle phases. These solar cycle phases are highlighted under the following criteria (Zerbo et al., 2011; Ouattara et al., 2012; Gnabahou \& Ouattara, 2012; Ouattara, 2013): (1) minimum phase: $\mathrm{Rz}<20$; (2) ascending phase: $20 \leq \mathrm{Rz} \leq 100$ and $\mathrm{Rz}$ greater than the previous year's value; (3) maximum phase: $\mathrm{Rz}>100$ [for small solar cycles (solar cycles with sunspot number maximum ( $\mathrm{Rz}$ max) less than 100) the maximum phase is obtained by considering $\mathrm{Rz}>$ $0.8 * \mathrm{Rz}$ max]; and (4) descending phase: $100 \geq \mathrm{Rz} \geq 20$ and $\mathrm{Rz}$ less than the previous year's value. In these previous inequations, $\mathrm{Rz}$ is the yearly average Zürich sunspot number.

For analyzing data time variation, the five typical foF2 time profiles in African EIA (Equatorial Ionization Anomaly) sector (Figure 3) shown by Fayot and Vila (1979) are considered. According to these authors we have 
the noon bite out profile or "B" profile (panel a), the morning peak profile or " $M$ " profile (panel $b$ ), the dome profile or "D" profile (panel c), the plateau profile or "P" profile (panel d) and the reverse profile or "R" profile (panel e).

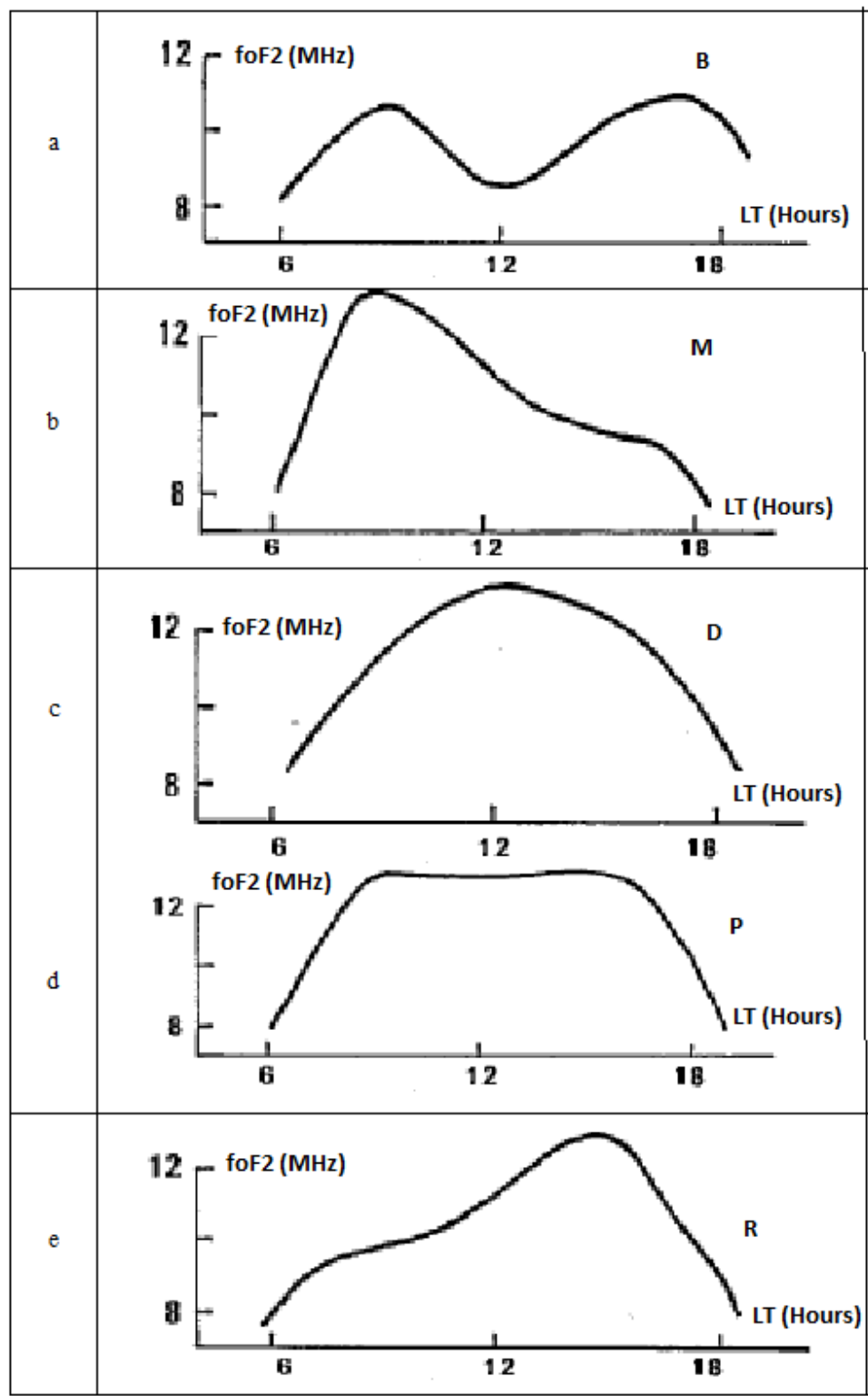

Figure 3. foF2 profile types after Fayot and Vila (1979) and taken from Gyébré et al. (2018). Panel a concerns noon bite out profile that expresses the signature of strong electrojet; panel $\mathrm{b}$ called morning peak profile and exhibits the signature of mean electrojet; panel c profile is dome profile and that of panel $\mathrm{d}$ is plateau profile

In the present study, the data are, carried out at Ouagadougou station, are compared with International Reference Ionosphere (IRI). This model is the result of an international cooperation that is under the supervision of the Committee of Spatial Research (COSPAR). Since the first used of the model in 1969, it is continuously improved each five years. Here is concerned the 2012 version of IRI.

For the comparison, the two subroutines Union Radio Scientifique International (URSI) and Comite Consultattif International des Radiocommunications (CCIR) are used. These subroutines computed values are compared with that of data for testing the model accuracy. 


\section{Results and Discussions}

The Figures 4, 5 and 6 concern foF2 time variation for one-day-shock, two-days-shock and three-days-shock, respectively. The panel a concerns the solar minimum phase, the panel $b$ is devoted the solar increasing phase, the panel $\mathrm{c}$ presents the time variation of foF 2 during the solar maximum phase and the panel $\mathrm{d}$ shows foF 2 diurnal variation during the solar decreasing phase. The dotted line shows foF2 time variation for CCIR subroutine, the broken line exhibits that of URSI subroutine and the full line is devoted to data time variation.

The Figure 4 shows that there is no data that concern on-day-shock. Through solar cycle phase and at daytime, foF2 profiles (Faynot \& Vila, 1979) have been reproduced by the model's subroutines. As these profiles highlight the ionosphere electrodynamics of this sector (Farley et al., 1986; Fejer et al., 1979; Fejer, 1981), this points out that the daytime, IRI is able to reproduce the ionosphere electrodynamics mechanism at this sector for one-day-shock. At nighttime, the experimental profiles show a nighttime peak that expresses the signature of the reversal electric field at this equatorial region (Farley et al., 1986; Fejer et al., 1979; Fejer, 1981), it emerges that IRI is not able to reproduce this signature during the occurrence of one-day-shock.

Moreover, from the analyzing of the morphology of the foF 2 time profile it can be retained that during the solar cycle increasing phase (panel b) and maximum phase (panel c) the best responses are given by CCIR while during the decreasing phase (panel d) URSI gives a the best one.

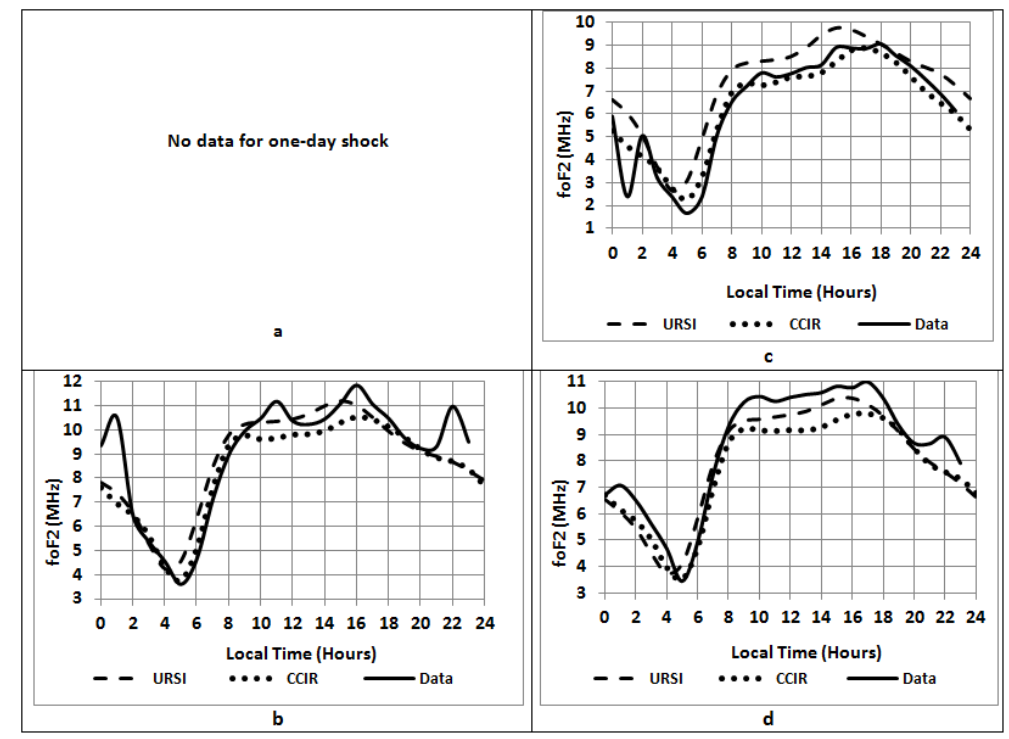

Figure 4. One-day-shock foF2 time variation for (a) minimum phase, (b) increasing phase, (c) maximum phase and (d) decreasing phase

The Figure 5 shows that during the minimum phase (panel a) and the increasing phase (panel b) all profiles shows the same reverse profile. This shows that IRI reproduces the daytime ionosphere electrodynamics during these solar phases. It can be also pointed out that the best responses are given by CCIR in panel a and by URSI in panel $b$.

The panel $\mathrm{c}$ exhibits that when the data profile is morning profile that of IRI profiles are plateau for CCIR and fairly reverse for URSI. Therefore, IRI doesn't reproduce the ionosphere electrodynamics. By taking account the gap between model's graphs and that of the data, we can assert that the best subroutine is URSI.

The analysis of the panel $d$ shows that data profile is plateau profile while those of the model are the reverse ones. IRI is not a suitable model during this decreasing phase. But by regarding the gap between data profile and that of model, it emerges that the best subroutine is URSI.

It can be retained that when occurs two-days-shock, URSI is the best model except during increasing phase where it is CCIR. IRI reproduces the electrodynamics effects during the minimum and the increasing phases.

The analyzing of the Figure 6 revealed that during the minimum phase (panel a) the IRI profiles are revers profiles and that of data is a noon bite out profile. By taking into account the gap between data profile and that of IRI, it can be noted that at daytime, in general, CCIR is the best 
During the solar increasing phase, the IRI graphs are the reverse profile while that of data is a noon bite out profile. The panel $\mathrm{b}$ shows that the best model is URSI by taking into account the gap between the data and that had carried out by using IRI model.

During the maximum phase, it can be seen that data and CCIR profiles are morning profile while that of URSI is fairly plateau profile. The gap analyzing shows that the best model is URSI at daytime while at night time and before sunrise the best model is CCIR.

For decreasing phase, one can see that data profile is fairly plateau profile while that of URSI is a revers profile and that of CCIR is fairly a noon bite out profile. At day time, the gap shows that URSI is the best. At night time and before sunrise the best model is CCIR.

The night time peak that reveals the signature of the pre-reversal enhancement of the electric field is shown by CCIR graph during the maximum phase (panel c) and during the descending phase (panel d).

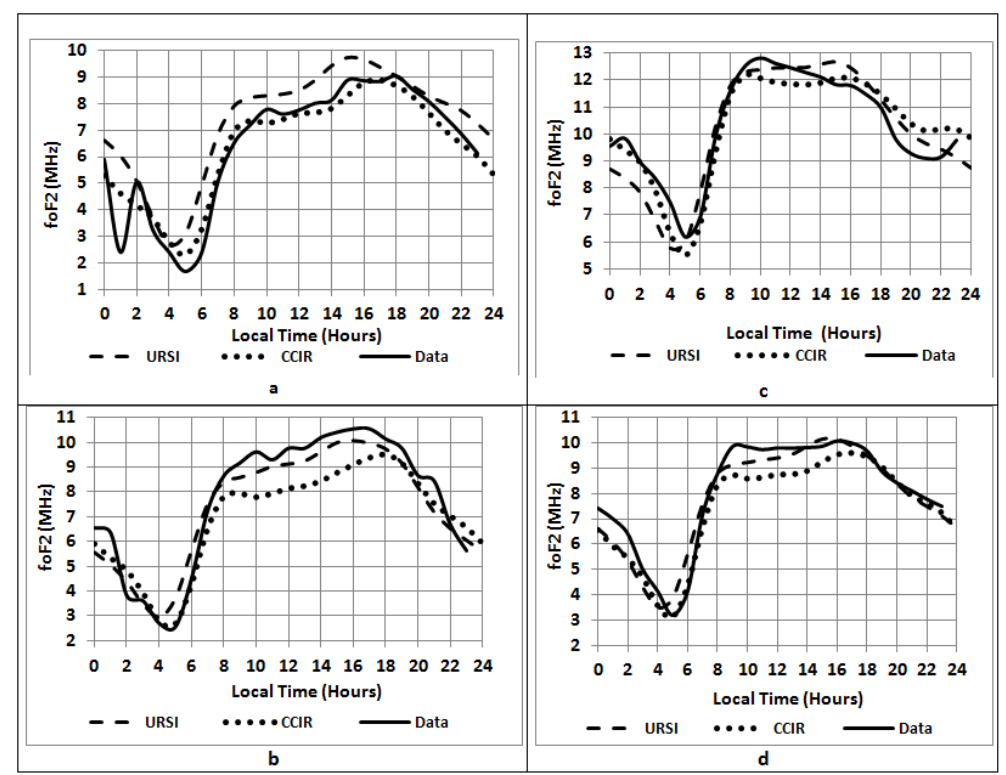

Figure 5. The same as Figure 4 but for two-days-shock

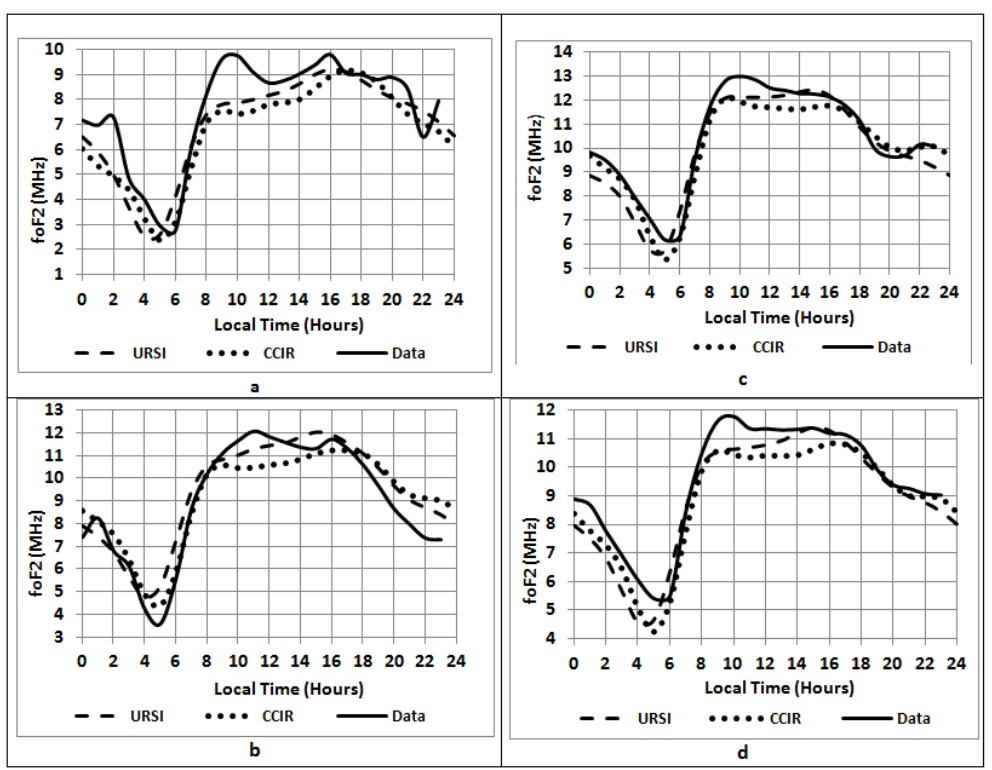

Figure 6. The same as Figure 1 but for three-days-shock 


\section{Conclusion}

From the present study, it emerges that during the solar minimum phase, there is no one-day-shock activity. For the other solar cycle phases, and at day time, it can be retained that during one-day-shock activity, IRI is able to reproduce the ionosphere electrodynamics mechanism at this sector except during the solar increasing phase. At night time whatever the solar cycle phase, the model graphs are not able to express data time variation and especially the signature of the night time reversal electric field. Moreover, from the analyzing of the morphology of the foF 2 time profile shows that during the solar cycle increasing phase and maximum phase the best responses are given by CCIR while during the decreasing phase URSI gives a the best one.

Under the two-days-shock activity and during the minimum phase and the increasing phase IRI reproduces the daytime ionosphere electrodynamics. It can be also pointed out that the best responses are given by CCIR during the minimum phase and by URSI during the increasing phase. During solar maximum phase, IRI is not able to reproduce the ionosphere electrodynamics. By taking into account the gap between model's graphs and that of the data, it emerges that the best subroutine is URSI. For solar decreasing phase, IRI is not a suitable model but by regarding the gap between data profile and that of model, the best subroutine is URSI.

During the three-days-shock activity, the present study shows that IRI is not a suitable model during the solar minimum phase. But the analyzing of the gap between data profile and that of IRI, shows that at daytime, in general, CCIR is the best. During the solar increasing phase, the IRI results show that it is not a suitable model. But considering the gap between data and computed values the best model is URSI. During the maximum phase, the gap analyzing shows that the best model is URSI at daytime while at night time and before sunrise the best model is CCIR. For decreasing phase, at day time, the gap shows that URSI is the best. At night time and before sunrise the best model is CCIR.

\section{Conflict of interests}

The authors declare that there is no conflict of interests regarding the publication of this paper.

\section{References}

Buonsanto, M. J. (1999). Ionospheric storms - a review. Space Science Review, 88, 563-601.

Farley, D. T., Bonell, E., Fejer, B. G., \& Larsen, M. F. (1986). The Prereversal Enhancement of the Zonal Electric Field in the Equatorial Ionosphere. Journal of Geophysical Research, 91, 13723-13728.

Faynot, J. M., \& Vila, P. (1979). F-Region at the Magnetic Equator. Annales Geophysicae, 35, 1-9.

Fejer, B. G. (1981). The Equatorial Ionospheric Electric Fields: A Review. Journal of Atmospheric and Terrestrial Physics, 43, 377-386.

Fejer, B. G., Farley, D. T., Woodman, R. F., \& Calderon, C. (1979). Dependence of Equatorial F-Region Vertical Drifts on Season and Solar Cycle. Journal of Geophysical Research, 84, 5792-5796.

Fuller-Rowell, T. J., Codrescu, M. V., Fejer, B. G., Borer, W., Marcos, F., \& Anderson, D. N. (1997). Dynamics of the low-latitude thermosphere: quiet and disturbed conditions. Journal of Atmospheric and Solar Physics, 59, 1533-1540.

Gnabahou, D. A., \& Ouattara, F. (2012). Ionosphere Variability from 1957 to 1981 at Djibouti Station. European Journal of Scientific Research, 73(3), 382-390.

Goncharenko, L. P., Salah, J. E., van Eyken, A., Howells, V., Thayer, J. P., Taran, V. I., Shpynev, B., Zhou, Q., \& Chau, J. (2005). Observations of the April 2002 geomagnetic storm by the global network of incoherent scatter radars. Annales Geophysicae, 23, 163-181.

Gyébré, A. M. F., Gnabahou, D. A., \& Ouattara, F. (2018). The geomagnetic effects of solar activity as measured at Ouagadougou Station. International Journal of Astronomy and Astrophysics, 8, 178-190.

Legrand, J. P., \& Simon, P. A. (1989a). Solar and Geomagnetic Activity: A review for Geophysicists. Part 1. The Contributions to Geomagnetic Activity of Shock Waves and of Solar Wind. Annals of Geophysics, 7, 565-578.

Legrand, J. P., \& Simon, P. A. (1989b). Solar and Geomagnetic Activity: A review for Geophysicists. Part II. The Solar Sources of Geomagnetic Activity and Their Links with Sunspot Cycle Activity. Annals of Geophysics, 7, 579-594.

Lu, G., Pi, X., Richmond, A. D., \& Roble, R. G. (1998). Variations of total electron content during geomagnetic disturbances: a model/observation comparison. Geophysics Research Letter, 25, 253- 256. 
Matsushita, S. (1959). A Study of the Morphology of Ionospheric Storm. Journal of Geophysical Research, 64(3), 305-320.

Mendillo, M. (2006). Storms in the ionosphere: Patterns and processes for total electron content. Review of Geophysics, 44(4), RG4001.

Ouattara, F. (2013). IRI-2007 foF2 Predictions at Ouagadougou Station during Quiet Time Periods from 1985 to 1995. Archives of Physics Research, 4, 12-18.

Ouattara, F., \& Amory Mazaudier, C. (2009). Solar-geomagnetic activity and Aa indices toward a standard classification. Journal of Atmospheric Solar and Terrestrial Physics, 71, 1736-1748.

Ouattara, F., Ali, M. N., \& Zougmoré, F. (2012). A comparative study of seasonal and quiet time foF2 diurnal variation at Dakar and Ouagadougou stations during solar minimum and maximum for solar cycles 21-22. European Scientific Journal, 1-14.

Ouattara, F., Kaboré, S., Gyébré, A. M. F., \& Zerbo, J. L. (2015). CMEs' shock occurrences from solar cycle 11 to solar cycle 23. European Journal of Scientific Research, 130(1), 153-159.

Pi, X., Mendillo, M., Hughes, W. J., Buonsanto, M. J., Sipler, D. W., Kelly, J., Zhou, Q., Lu, G., \& Hughes, T. J. (2000). Dynamical effects of geomagnetic storms and substorms in the middle-latitude ionosphere: An observational campaign. Journal of Geophysical Research, 105, 7403-7417.

Prölss, G. W. (1995). In H. Volland (Ed.), Ionospheric F region storms, in Handbook of Atmospheric Electrodynamics (pp. 195-248). CRC Press, Boca Raton, Fla.

Richardson, I. G., \& Cane, H. V. (2002). Sources of Geomagnetic Activity during Nearly Three Solar Cycles (1972-2000). Journal of Geophysical Research, 107, 1187.

Richardson, I. G., Cliver, E. W., \& Cane, H. V. (2000). Sources of Geomagnetic Activity over the Solar Cycle: Relative Importance of Coronal Mass Ejections, High-Speed Streams, and Slow Solar Wind. Journal of Geophysical Research, 105, 18200-18213.

Sahai, Y., Fagundes, P. R., Becker-Guedes, F., Abalde, J. R., Crowley, G., Pi, X., Igarashi, K., Amarante, G. M., Pimenta, A. A., \& Bittencourt, J. A. (2004). Longitudinal differences observed in the ionospheric F-region during the major geomagnetic storm of 31 March 2001. Annales Geophysicae, 22, 3221-3229.

Sahai, Y., Shiokawa, K., Otsuka, Y., Ihara, C., Ogawa, T., Igarashi, K., Miyazaki, S., \& Saito, A. (2001). Imaging observations of midlatitude ionospheric disturbances during the geomagnetic storm of February 12, 200. Journal of Geophysical Research, 106, 24481-24492.

Sastri, J. H., Niranjan, K., \& Subbarao, K. S. V. (2002). Response of the equatorial ionosphere in the Indian (midnight) sector to the severe magnetic storm of July 15, 2000. Geophysics Research Letter, 29.

Yizengaw, E., Dyson, P. L., Essex, E. A., \& Moldwin, M. B. (2005). Ionosphere dynamics over the Southern Hemisphere during the 31 March 2001 severe magnetic storm using multi-instrument measurement data. Annales Geophysicae, 23, 707-721.

Zerbo, J. L., Ouattara, F., Zoundi, C., \& Gyébré, A. M. F. (2011). Cycle solaire 23 et activité géomagnétique depuis 1868. Révue CAMES-Série A, 12(2), 255-262.

\section{Copyrights}

Copyright for this article is retained by the author(s), with first publication rights granted to the journal.

This is an open-access article distributed under the terms and conditions of the Creative Commons Attribution license (http://creativecommons.org/licenses/by/4.0/). 